\title{
ROLE OF CIVIL SOCIETY IN GENDER EQUALITY: SOCIOLOGICAL PERSPECTIVES
}

\section{K. M. Ziyauddin, $\mathbf{P h D}^{1 *}$}

*1 Department of Sociology, School of Arts \& Social Sciences Maulana Azad National Urdu University, Hyderabad. IndiaE-mail: ziyakm@manuu.edu.in

*Corresponding Author: -

E-mail:ziyakm@manuu.edu.in

\begin{abstract}
: -
Compared to previous studies on gender equality, such as work, democracy, and welfare, or caste, religion, and family, the studies have placed little or no attention on the connections between civil society organisations, and gender equality or even on relationships between civil society bodies/organisations and gender equality has garnered little or no attention. In this paper, I propose a paradigm for analysing the role of civil society in gender equality, in which civil society is viewed as a critical pillar in advancing the cause and providing the wheels that propel gender equality for men and women (he or she). On the one hand, gender mainstreaming, which is concerned with the study of gender equality practises both inside and outside of organisations, in economic spheres, political activism, parting roads in governance, and volunteerism in activities and projects aimed at promoting gender equality in the larger community, is important.
\end{abstract}

Keywords: Gender, Civil Society, Equality, Sociological, Feminism, Nation and India. 


\section{EPILOGUE}

Compared to previous studies on gender equality, such as work, democracy, and welfare, or caste, religion, and family, the studies have placed little or no attention on the connections between civil society organisations and gender equality of the relationships between civil society organisations and gender equality has garnered little or no attention. In this paper, I propose a paradigm for analysing the role of civil society in gender equality, in which civil society is viewed as a critical pillar in advancing the cause and providing the wheels that propel gender equality for men and women (he or she). On the one hand, gender mainstreaming, which is concerned with the study of gender equality practises both inside and outside of organisations, in economic spheres, political activism, parting roads in governance, and volunteerism in activities and projects aimed at promoting gender equality in the larger community, is important.

Empowerment, capacity growth in terms of organisational mission, participation, management, responsibility, strategic capabilities, and involvement in the communities and inter-organizational networks (Edwards and Fowler, 2002), among other things, are essential for all gender equality dialogue and interventions. The intersection of these two sorts of axes raises questions of efficacy and sustainability in civil society organisations as well as in the context of gender equality, and provides a richer framework for research, policymaking, and even academic work.

One of UN Women's most significant constituents is civil society. It's a constant supply of new ideas, policy viewpoints, collaborations, and support. UN Women's cooperation with civil society has been strategic and inventive since its inception in 2011, with the goal of strengthening political unity and feminist movement building. This partnership is based on the philosophy of leaving no one behind, as well as the fact that women and girls face intersectional discrimination due to their gender, colour, class, sexual identity, and other factors. One of the most important aspects of this strategy is to prioritise the advancement of the most underprivileged populations.

Another aspect of this strategy is at the international, regional, and county level, the establishment of Civil Society Advisory Groups levels (CSAGs). At all of these levels, the CSAGs function as forums for debate and continuous participation. They help UN Women stay connected to the issues and people we serve.

\section{Making Gender visible by Usage}

How can we explain this phrase if we believe that inequality exists in a variety of forms? Bourdieu identified three categories of inequality, each of which corresponds to a distinct type of 'capital.' Access to money is referred to as economic capital. The social relationships and institutionalised networks of which an individual is a part are referred to as social capital. Knowledge or abilities earned through education, cultural commodities, and qualifications are all examples of cultural capital. Each sort of capital is influenced by the others, and Bourdieu's primary concern is how privileged groups use them to reproduce privilege.

Gender inequality refers to persons being treated unequally based on their gender identity. Gender inequality is the result of socially established gender norms based on cultural differences. Gender inequality, often referred as gender discrimination, applies to both genders male and female with certain unequal rights by the virtue of socially constructed gender roles that usually results into differential treatment in everyday life. Inequality based on gender lines as an idea remains a historical fact for years, and until the beginning of the twentieth century it became a reality that it became "one of the most fast, dramatic social shifts" (Wright \& Rogers 2009).

Gender has been part of the ordinary social science lexicon in the last 40 years, thanks to the feminist movement and associated scholarly endeavours to better comprehend women's systemic and widespread oppression, subjugation and dominance by men. Even among feminist researchers, there is no consensus on the definition of the phrase, despite its widespread use (Butler 1990).

Gender was originally used to emphasise the social and relational character of disparities between men and women, as opposed to biological ones. Gender was predetermined by nature, whilst sex was regulated by upbringing. Gender roles supplanted sex roles in sociology because gender more accurately described the social construction of roles and behaviours that separate societies into two identities men and women. Gender and sex were intertwined but distinctive around the same time. Gender was sociological and therefore changeable over a period of time, but sex in real sense reflected the intrinsic and unchangeable physiological differences in individual reproduction. Between sex and gender, there was an implicit causal relationship (ibid, 1).

As a result, one can deduce that gender inequality refers to unequal treatment of men and women, but I'm more interested in discussing the unfair treatment of women. Domestic violence and sexual assault are far more likely to happen to both women and men, while domestic violence and sexual assault are more likely to happen to women. In certain nations and cultures, males have lower educational attainment than females, whereas in others, the opposite is true. Excluding current NFHS statistics showing females outnumbering men in the sex ratio, gender disparity in demographics include the fact how men as one segment of biological sex live shorter life lives in contrast to other sex, women.

\section{The global problems of gender inequality:}

Despite regional and international efforts to promote gender equality, egregious disparities continue to exist throughout the world in gender norms. Costa Rica, Cuba, Sweden, and Norway are the only four countries out of over 135 that have achieved gender equality. Yemen had the lowest score in every category. Access to fundamental learning by education, quality health and life expectancy, political equality and economic justice are all indicators of gender equality. Despite visible progress, many grave concerns involving gender discrimination persist today; consequently, as a critical step for both human and economic growth, total gender parity must always be made a international priority.

Gender inequality varies in severity and causes around the world. Violence, feticide (women's murder), and rape are all examples of crimes against women (war rape). The killing of a female person of any family in the name of honour, such 
incidents are popularly referred as honour killing as person is bringing dishonour to the family. Female infanticide is another persistent element that reflects inequalities based on gender or bias towards women.

Sex-selective abortion supports trafficking of human population, demographic disparities, and sexual abuse, all of which are major consequences of gender inequality. Informally, both India and China, the world's two most populous countries, maintain this bias for male childbirth over female childbirth. In India, the birth of a male is regarded as a blessing, whereas the birth of a girl is regarded as a burden in the family and society. Sex-selection is undoubtedly a violation of rights to life, and in nations where it is prevalent, real sex ratios of 50/50 have been changed.

\section{An example by a Historical Sketch:}

Gender equality was formally introduced in agenda of the SAARC at $6^{\text {th }}$ summit held in the year 1991. In same year the organisation announced the "Decade of the Girl Child, 1991-2010", and produced a National Plan of Action in order of promoting Girl's right in the states having membership with SAARC, in conjunction with UNICEF. SAARC's early development-focused approach, on the other hand, has been questioned by feminist organizations for failing to adequately addressing gender-based power hierarchies, inequities, stereotypes, and prejudices. As a result, while this strategy attempted to include women in the economic growth and poverty framework, it had the reverse effect; it did not succeed in establishing national policies to promote gender equality in social processes (Tuladhar 2013).

SAARC didn't start addressing the lack of significant political participation of women in politics of South Asian societies until 2007, when it unveiled the SAARC Development Goals 2007-2012, especially Goal Eight ensuring proper participation of the Women and the disadvantaged are included in anti-poverty programs and policies. One also finds that the SAARC previously treated women as objects rather than officials in the development phase.

After 13 meetings since its inception in 1986, Technical Committee of Women in Development got merged into the Technical Committee for Social Development in January 2000. Later in a meeting, it was renamed the "Technical Committee on Women, Youth, and Children under the Regional Integrated Programme of Action of 2004". Since then seven different meetings are held and the last was held in Islamabad in the year 2015. Gender concerns, as well as children and youth issues, are addressed in its sessions.

A Memorandum of Understanding was signed in 2001 between SAARC and UNIFEM, which later became UN Women. Both in 2007 and 2014, this was extended for another six years. In compliance with global arrangements; namely "Beijing Plus Five Outcomes Document", SAARC Sustainable Development Goals 2007-2012, the Millennium Development Goals and Sustainable Development Goals". The Memorandum offers a framework for UN Women and members of SAARC nations to collaborate in the promotion of gender equality.

As a result of this partnership, the SAARC Gender Information Base (SGIB) was established. It now supports as a source of data deriving out of qualitative and quantitative methods on the issues of gender and empowerment of women in South Asia. The SGIB gathers information on three major topics: Women's health, feminization of poverty, and gender - based violence. It directly engages and involve through actions and works with ministries allocated at the SAARC local and state level, which puts apart from other SAARC projects.

The SGIB is regularly reviewed, with the most recent one occurring in the city Islamabad in 2014 (United Nations Women, SASRO, SAARC, 2012). The SAARC adopted a "Standard Operating Procedure" to prevent trafficking of humans and use of women in prostitution after adopting the "Regional Convention on Combating the Crime of Trafficking Women and Children for Prostitution in 2002".

\section{Where do we locate gender equality?}

As gender equality becomes a more prominent policy concern in state policies and at the EU level, it has become clear that a more multidimensional approach is needed to account for the interactions that develop between the state and civil society (Lange and Trukeschitz, 2005).

In addition to supporting other organisations, a gender equality approach is important. These organisations are critical for expressing the concerns of women and establishing a constituency for gender equality and creating inclusive space for all citizens (Ziyauddin and Begum, 2021). For instance, trade associations/unions have to represent both male and female members, environmental lobbying groups should consider the impact of environmental issues on both men and women, and poverty organisations should understand how poverty affects both men and women and what methods will help both. The more mainstream organisations campaign for greater gender equality, the less likely these issues will be dismissed as a "special interest group."

Gender inequality has many sides and can be found in the demographic, social, political, and economic domains of every society built on egalitarian principles. In these directions, gender equality in the labour force, civil society and third-sector organisations' contribution involvement in advancing gender equality are important.

\section{Gender Inequality's Characteristics:}

When compared to other kinds of inequality like class, caste, race, ethnicity has certain distinguishing qualities. Gender inequality originates from distinctions, whether objectively based or socially manufactured, as these unique qualities demonstrate.

\section{Three features of gender inequality (Bina Agrawal):}

1. Gender inequality is prevalent not only outside but also inside the house;

2. Gender inequality is caused not just by pre-existing differences in economic resources (capital, finance or income, etc.) amongst men and women, The inequities are philosophically entrenched, but also by pre-existing socially constructed norms which is gendered and perceptions constructed socially; and 
3. Gender inequalities can originate not just from pre-existing gender inequalities, but also through newly defined norms and procedures that regulate the governing institution's functioning. For example, CPR (Common Pool Resources) institutions are governed by regulations that might either expressly or tacitly reject certain people, groups of the communities, such as females, from decisionmaking institutions and privileges.

Understanding gender inequality indicators is critical to tackling gender-related problems and concerns because they show where, why, and how disparity based on gender occurs. These indicators to measure are critical what is measured has a higher chance of being prioritised, and information obtained against indicators can assist indicate which gender concerns should be addressed. Indicators can be utilized in advocacy to help make the argument for actions by highlighting important problems and providing data and other facts to back them up.

This opens the door for the emergence of civil society initiatives to work assiduously and vociferously on issues of gender equality. Many organisations, such as "United Nations Development Programme, United Nations Economic and Social Council in 2008 and Organization for Economic Cooperation and Development, World Economic Forum" (Thorsten, 2011), and others, have created a number of indicators. The other indicators created are" Gender Development Index (GDI)"; "Gender Empowerment Measure" that is developed by the UNDP. The "Gender Institutions and Development" (GID) database was created by the OECD. The Gender Gap Index (GGI) (Lopez and Zahidi, 2011) was established by the World Economic Forum, and the MDGs as reported in a document by United Nations (2006) that discusses assessing indices of gender disparity. (Global Gender Gap Report 2016 by the World Economic Forum)' As a result, several indicators are employed to measure gender inequality on a regular basis. These global and regional gender indices stands valuable because they permits cross-national gender inequality comparisons and compress diverse data into straightforward messages about the amount of global gender disparity.

Different Facets of Gender Inequality: It is a commonly understood factor that gender Inequality has multiple facets: demographic, social, political, economic Inequality and they are given in the following:

Economic Facets of Gender Inequality- Women, families, and gender studies were classified as sociological rather than economic concerns. To back up this claim, economics has long ignored topics that disproportionately affects the woman folk who are unpaid domestic labour, intra-family economic interactions, discrimination in labour market, emotional and social elements of human relations. When it was understood that "the opportunity cost of excluding women from the economy is too expensive for any society," economics became interested in gender inequality. Only in the 1970s was the experience of women in paid labour and in families studied in economics, and anyway, reductionist perspectives predominated.

Economists across the globe have researched the financial part of gender inequality using a variety of variables including education, income level, work participation and employment, earnings gap, economic involvement, ownership rights, asset control, rate in work participation, and so on so forth.

The picture has evolved dramatically over time. Women's contribution to economic progress is widely acknowledged. Numerous studies have been conducted to provide light on the significance of women development of economy and largest excluded group out of total population (Human Development Report, 1993). Despite the fact that they account for half of the adult population and frequently contribute far more to society than their fair part, both inside and external to the house, they are typically kept out of positions of power. Women are underrepresented in the labour force, and women's earnings in some developed countries are lesser than half of man's for over decades.

Gender discrimination comes in a variety of shapes and sizes that retained its face for years. According to Amartya Sen (2001), gender disparity exists in almost every country (including Japan to Morocco, or from the range countries Uzbekistan to the United States. However, inequality between both men and women does not exist everywhere in the same scale and severity. It can come in a variety of shapes and sizes. Gender inequality is a collection of various and interconnected issues, rather than a single reality. He has also identified seven different categories of gender inequality, viz;

1. Inequality in Mortality

2. Inequality in Natality,

3. Inequality in providing basic facilities,

4. Inequality in giving special opportunity,

5. Inequality in Professionals Field,

6. Inequality in Ownership and

7. Inequality at the household level.

As a result, many aspects of gender inequity colour people's life from the moment we are born until we die. Not only women and girls in particular, but even men and boys at large, suffer as a result of many forms of gender discrimination. In India, the current women's movement is placed against the backdrop of the social reform movement and the nationalist drive for independence (Mazumdar 1976). What role did these movements have in boosting women's education? What role did the early women's movement play in setting the educational agenda for women? But, in this paper, the attempt was to understand civil society's role in achieving gender equality, rather than situating it in the historical context of reform and nationalist movements, it is limited in the same domain while discussing. 


\section{Who are civil societies?}

The term "civil society" refers to a group of persons who have shared interests and engage in cooperative activities ("they make important contributions to civil society). It encompasses a wide spectrum of non-profit and non-governmental organisations that allow public and member interests and beliefs to be expressed for historical, moral, ideological, humanitarian, logical, and religious purposes.

\section{The Role of Civil Society}

The new women's movement began in the late 1960s and early 1970s as a powerful voice of women and their struggle against injustice and for an equalitarian social space for women in the society. Women activists promoted awareness of the various areas in which women were oppressed and brought these issues to the public's attention, frequently through the media. They challenged our society's distinctions between public and private spheres, paid and unpaid employment, and care, among other things. These organisations have also served as important learning environments for women learning organisational and advocacy abilities. Female researchers began gathering statistics and data, demonstrating women's secondary standing in society, simultaneously women's organisations were re-vitalized. Norwegian society was found to be gendered and segregated along gender lines, according to feminist study. Some women activists went into politics, while others went into research, and still others were involved in all three. Gender research has created a huge corpus of work over the years.

Furthermore, women in politics pushed these issues in parliament, informed by women's research and organisations, and brought about changes in the law. Although there have been some frustrations and disagreements along the way, the relationship between non- governmental organisations and the Norwegian authorities has largely improved. Furthermore, between research, non-governmental organisations, and the state, beneficial cooperation and open conversation have evolved, worthy of a functioning democracy. The media also play a critical role in bringing up the issue of gender in public debate, which is critical for building and sustaining societal ideals.

Connect between civil/liberal society and the state and gender can be studied and seen in a variety of fields. The history of the connection between civic society and women is extensive. It dates back to the history of antislavery movement in $18^{\text {th }}$ century, when few women advocated, developed strategies to lobby by using respective churches in Europe and Western Countries. Furthermore, in late $19^{\text {th }}$ and early $20^{\text {th }}$ century, women's movement to attain suffragettes in USA and UK advocated for equality in electoral field between women and men. Women were also active in various nationalism movements across the Middle East during the dissolution of the Ottoman Empire. The bond grew even deeper with the peace action programmes during the second half of $20^{\text {th }}$ century. Anti-nuclear weapons activism was one of the most major platforms here. Women's protests on Greenham Common in the United Kingdom afterward 1981 shows a good example of how civil society and gender interact in the UK (Harford and Hopkins, 1984).

The movements of civil society bodies (at either level local, national, and international levels) play an important role in advancing women's rights, influencing national policymaking, ensuring the development and implementation of gender equality policies, and ensuring states' compliance with various international gender equality charters.

Supporting the establishment of a civil society groups that represents interest of both women and men and encourages active involvement by all individuals (men and women) can be accomplished by paying attention to:

$>$ Organizational membership expansion capabilities - Is there any effort by organisations in reaching out men and women and inspire or encourage them to participate? Is there an unofficial gender divide in the workplace, with women in charge of particular tasks or fields of activity and males in charge of others? Is there an unspoken gender divide in the workplace in which women are accountable to carry out any tasks or certain activities while men are responsible for any other field?

$>$ Equal-opportunity organisations' capacity - Is there a plan in place to provide resources and technical assistance to organisations that are solely focused on gender equality? Is there a way for those organisations to connect with other like-minded organisations, both locally and globally, to learn and know from each other?

$>$ Gender prejudices and biases, on both men and women's sides, must be eliminated - Do organisations work together with men and women to address challenges of gender equality and empower women leaders? Is it encouraged for men and women to work in non-traditional industries to broaden their perspectives?

$>$ NGOs regularly engage with communities and individuals with the goal of integrating them into specific programmes or projects, and gender-sensitive participatory strategies are being developed. Even when using participatory processes, extra steps must be taken to ensure that both men and women are able to participate equally. If gender inequities and power discrepancies are not addressed in community dialogues, only a small number of perspectives will be heard.

There are certain ways to get rid of Inequality but one can also think and question to understand certain ideas as mentioned following;

$>$ Changing people's attitudes through educating them about women's rights, as well as their contributions and importance in society.

$>$ Educating women to help them break free from their guardians' control and become self-sufficient and fearless.

$>$ Making women aware of the limitless opportunities for making a living and safeguarding their future by launching their own business. 
Further, a few micro level examples of Civil Society Initiatives that demand a lot field level micro studies that provides some nuances about gender equality and there are two instances mentioned here;

$>$ Rising Tree Foundation. Various programmes under rising tree enlighten centres benefited and empowered over 2000 mothers and girl children. The team of the foundation provided health care and disaster aid to over 5000 girls and women in their homes. Many more were given adequate health-related information, such as issues, schemes, and so on. Some of them were given training to become "change makers" so that they could continue to volunteer in their local communities. Currently enrolled in all centres in 2021, more than 100 poor girls attend remedial education and training on a regular basis.

$>$ Safa Society- Hyderabad is another grassroot organization that sustainably worked over the last one decade. It is important to compare the works involving concerning women livelihood and education that Safa society has worked in the past.

\section{So where is the way?}

* To be really democratic, civil society organisations must be able to represent the concerns and interests of both male and female members. Gender equality is a broad social issue that falls beyond of the purview of women's organisations.

* It is necessary to review mainstream organisations' capacities to guarantee that their activities include and benefit both men and women, develop women (as well as men) leaders, and promote gender equality (whenever possible).

* Although the women's movement in India and South Asian countries have started playing significant role similar to western countries in recent years, organisations still require money and technical assistance.

* Gender equality and gender equality supporters may gain more credibility if these organisations are included in mainstream discourses, coalitions, and actions.

— Discussions about gender equality should be treated with caution, keeping the historical legacy and specific reality in mind.

\section{Conclusion}

Any democratic society requires a vibrant civil society. The NGO's (non-governmental organisations) do play crucial role in the area of gender equality, may be limited. Governments are held accountable, citizens' needs and interests are expressed, change is lobbied for, research is performed, constituencies are developed and mobilised and direct services are supplied. NGO experience is still very new and fragile in many countries, including India. Organizations are laying the groundwork for their foundations, increasing their capacity, developing their infrastructures, and defining their roles. Both key concerns from the perspective of gender equality present considerable challenges. Organizations formed by Women and gender-based equality campaigners in the region, on the other hand, are having quite differing viewpoints and approaches to attempt in this area.

As a result, a thriving civil society is critical in a democratic society that belief and inculcate democratic practices. Nongovernmental organisations (NGOs) play a vital role. Governments are held accountable, citizens' needs and interests are expressed, change is lobbied for, research is performed, constituencies are developed and mobilised and direct services are supplied. The roles played by a civil society in all developing world and in developed societies are remarkable at large. Any sociological attempt to look at the efforts and engagements demand a qualitative and intensive research and more than theoretical examinations.

\section{References}

[1].Agrawal, Bina. 2007. Gender Inequality, Cooperation and Environmental Sustainability. In Banand, JeanMarie, Bardhan Pranab and Bowles Samuel (Eds.), Inequality, Cooperation and Environmental Sustainability, Princeton University Press, New York, pp.274-276

[2].Al-Ali, N. 2003. Gender and civil society in the Middle East. International Feminist Journal of Politics, 4(2), $216-$ 232.

[3].Cahoone, L. E. 2002. Civil society: The conservative meaning of liberal politics. London: Blackwell.

[4].Carver, T. 1998. A political theory of gender: Perspectives on the "universal subject", In V. Randall and G. Waylen (Eds.), Gender, politics and the State. London: Routledge.

[5].Cockburn, C. 2007. From where we stand: War, women's activism and feminist analysis. London: Zed Books.

Howell, J. 2006. Gender and civil society- Global civil society Year Book. London: Sage. https://gender.no/gender-equality/the-role-of-civil-society

[6].Sen, Amartya. 2001. Many Faces of Gender Inequality, Frontline, Volume No. 18, Issue No.22, United Nations, The world's women 1995: Trends and statistics. New York, 1995.

[7].Ziyauddin, K.M. and Mumtaz Begum. 2021. Social Inclusion of Minorities and Equal Opportunity Commission In India: A Journey towards Equality", Equal Opportunity and Inclusion: Gender and Minority. Ed. Shahida and Amir Ullah Khan, Hyderabad: CDPP.

[8].Ziyauddin, K. M. 2021. The Role of Civil Society in Gender Equality: Sociological Perspectives, a paper presented in an invited talk in a webinar series organized by ParulUniversity, Jaipur, 16 Dec. 2021 